\title{
El archivo melancólico
}

\section{The Melancholic Archive}

\author{
Rodrigo García de la Sienra \\ Universidad Veracruzana, México \\ rodrigo.delasienra@gmail.com
}

Resumen: En este artículo la noción de archivo no es abordada en tanto simple forma de registro, sino como una serie de prácticas estéticas y ético-políticas destinadas a incidir en el entramado de la memoria y la historia, que incluso ha llegado a conformarse en paradigma. Mediante un breve recorrido conceptual de corte histórico-genealógico, se sugiere una ruta teórica para interrogarse acerca de las bases éticas y epistemológicas de las prácticas del archivo en el contexto contemporáneo.

Palabras clave: archivo, desapropiación, estética, melancolía, memoria, necroescritura.

Abstract: In this paper the concept of archive is not treated just as a simple form of register, but rather as a series of aesthetic and ethical-political practices that are aimed to influence upon the memory/history framework that has come to conform a paradigm. Through a brief historical-genealogical conceptual trip, a theoretical route is suggested in order to be able to interrogate ourselves about the ethical and epistemological bases of the archive practices in the contemporary context.

Keywords: Archive, Misappropriation, Aesthetics, Melancholy, Memory, Necrowriting. 
Recibido: 10 de abril de 2019

Aceptado: 14 de agosto de 2019 https://dx.doi.org/10.15174/rv.vi25.456

Los espectros, lo mismo que las alegorías profundamente significativas, son fenómenos procedentes del reino del luto; surgen atraidos por el entristecido, que rumia sobre los signos y el futuro.

Walter Benjamin. EL origEN DEL Trauerspiel aLEMÁN

\section{(D)escribir el archivo aquí, ahora}

La presente reflexión es una rumia sobre los signos y el futuro, animada por el deseo de resistir a la tristeza: un intento por comprender y mejorar nuestra condición existencial en el reino no sólo del luto, sino también de lo ominoso y lo espectral. Pues en efecto, hoy en día, pensar el archivo desde Latinoamérica, y particularmente desde México, difícilmente puede estar al margen de la necesidad colectiva de esbozar procedimientos para la negociación con los espectros. Así lo manifiesta por ejemplo Cristina Rivera Garza, cuando indaga acerca del sentido que puede revestir la escritura en un contexto regido por aquello que Achille Mbembe ha denominado necropolitica, es decir, un entorno en el que la soberanía política reside llanamente en el poder de decidir quién debe vivir y quién morir. Un contexto en el que el poder es ejercido por máquinas de guerra desterritorializadas que operan sobre la premisa de que la violencia no es monopolio del Estado y de que los ejércitos regulares no son ni el único ni el mejor agente para su ejercicio. 
El fenómeno narcotráfico en México es un claro ejemplo de ello. Resulta evidente, en efecto, cómo en nuestro país estas máquinas de guerra cumplen múltiples funciones que van desde la operación mercantil hasta la organización política, y cómo han logrado dispersar el "centro del mal" del que hablaba Bolaño en 2666 hacia la totalidad de la geografía nacional, convirtiendo campos y ciudades en auténticas "necrópolis contemporáneas". Y no cabe duda de que eso es lo que lleva a Rivera Garza a preguntarse:

¿Qué significa escribir hoy en este contexto? ¿Qué tipo de retos enfrenta el ejercicio de la escritura en un medio donde la precariedad del trabajo y la muerte horrísona constituyen la materia de todos los días? ¿Cuáles son los diálogos estéticos y éticos a los que nos avienta el hecho de escribir, literalmente, rodeados de muertos? (2013: 18-19).

Los muertos indóciles constituye un ensayo, una tentativa de respuesta a esas preguntas. Respuesta que Rivera Garza despliega a través de las dos nociones que aparecen en el subtítulo del libro y que lo organizan conceptualmente: necroescritura y desapropiación. $\mathrm{Si}$, como lo expresa esta escritora, la Comala de Rulfo "ha dejado de ser un mero producto de la imaginación [...] para convertirse en la verdadera necrópolis en la que se genera el tipo de existencia (no necesariamente vida) que caracteriza a la producción textual de hoy"; y si, además, por su parte "el narrador por excelencia del mundo actual" resulta ser ni más ni menos que el forense (2013: 36-38), escribir equivale entonces a generar "fichas anamnésicas" que son a la vez "cadáveres textuales". Pues es la propia realidad la que obliga a ir a contracorriente de la ideología organicista que conceptualiza la escritura en términos de germinación y parto, y a que los escritores se comporten como forenses, o lo que es lo mismo, como archivistas minuciosos que cuando leen, excavan y 
exhuman voces, no para apropiárselas, sino precisamente para desapropiarse de sí, es decir para establecer con y a través de ellas una relación de desposesión.

Archivista melancólico, el escritor asume las prácticas de la memoria como una forma de duelo fundada en la conciencia de nuestra común vulnerabilidad, así como en la premisa básica del ethos de la desapropiación que indica que "en el inicio estaba el nosotros". Un nosotros que, como expresa Rivera Garza en consonancia con Judith Butler, "es la forma más íntima y también la más política de acceder a mi subjetividad" (2013: 123).

Es sobre esta base que numerosos escritores habrían incorporado los métodos del montaje y el collage, influidos no sólo por la estética de las vanguardias, sino también por los métodos de la historia social:

Emulando en este sentido el muy relevante papel del archivo en las artes plásticas, donde ha pasado de ser un mero sistema de registro a convertirse en una obra en sí misma, algunos escritores no sólo buscan aprovechar la anécdota interesante o anómala sino, sobre todo, la estructura porosa, incompleta, lagunar, frágil del archivo en la escritura de sus novelas o sus poemas. El archivo, así, no da pie a la novela; la novela, en cambio, aspira a encarnar las vicisitudes del sistema de registro mismo, eso a lo que Derrida llamaba con razón el momento político de la archivación como productor de acontecimientos (Rivera Garza, 2013: 100).

Así, el archivo resulta ser no tanto un sistema de registro como una práctica artística, literaria y hermenéutica destinada a "producir acontecimientos" a través de su incidencia en la urdimbre que religa presente y pasado, es decir, una práctica que aspira a lograr una (re)organización ético-política de la memoria. 


\section{El archivo como paradigma}

En un libro dedicado al ámbito de las artes visuales, Arte y archivo. Genealogías, tipologías y discontinuidades, Anna María Guasch plantea la existencia cabal de un paradigma artístico del archivo, opuesto a otros dos grandes paradigmas conforme a los cuales se habría organizado el arte de las primeras vanguardias. El primero de ellos sería, según esta autora,

el de la obra única en la que la concepción y la ejecución constituyen un todo cuya aportación reside en la ruptura formal y cuyo carácter de singularidad se deriva, por lo tanto, de su efecto de shock; un paradigma propio de los lenguajes e ismos de las vanguardias históricas desde el Fauvismo y el Cubismo analítico hasta el Neoplasticismo y el Constructivismo. El otro gran paradigma es el de la multiplicidad del propio objeto artístico, el de su reversibilidad, como sería el caso del collage o del fotomontaje, dominado por la discontinuidad del espacio-soporte, pero también el de sus fisuras y disparidades o, estrictamente, el de la destrucción de los cánones tradicionales en la definición del objeto artístico, como se da en el Dadaísmo y, en algunos aspectos, en el Surrealismo (2011: 9).

La existencia de este "tercer paradigma" se deriva de una praxis artística guiada por la distinción entre el mero almacenamiento y el archivamiento propiamente dicho: pues "si el almacenar o coleccionar consiste en 'asignar' un lugar o depositar algo -una cosa, un objeto, una imagen - en un lugar determinado, el concepto de archivo entraña el hecho de "consignar" (Guasch, 2011: 10). Por supuesto, como lo expresara el propio Derrida en Mal de archivo -a quien la autora alude-, desde esta perspectiva la consignación implica "unificar, identificar, clasificar", esto es, "coordinar un 'cor- 
pus' dentro de un sistema o una sincronía de elementos seleccionados previamente en la que todos ellos se articulan y relacionan dentro de una unidad de configuración predeterminada" (Guasch, 2011: 10). La práctica artística regida por el paradigma del archivo renuncia en buena medida a fundar su estructura orgánicamente a partir de la fantasmagoría del origen, y más bien se asume como una estructura descentrada y como una multiplicidad serial. Además, su labor no rehúye la contradicción, en la medida en que su punto de partida está conformado por materiales frecuentemente considerados como banales o deleznables, y por la necesidad de confrontar productivamente el carácter eventualmente lacunario o inconsistente de sus propias colecciones. En suma, el paradigma del archivo prioriza, frente a la pura conceptualización de determinadas prácticas artísticas, las estrategias que permiten reflexionar sobre la manera en la que el pasado actúa y aparece en las formas del presente. En consecuencia,

las distintas prácticas del archivo suponen no sólo reescribir una historia descentrada a partir de un entrecruzamiento de distintos marcos sociales, sino plantear una reorientación radical en la representación y experiencia del espacio y el tiempo que implique una nueva lógica de la representación cultural, una determinación de la memoria cultural que se desligue de la historia como progresión lineal y finalista, y una superación del propio archivo como origen tipológico y registro del tiempo contingente, es decir, del archivo "de procedencia" del siglo xIx (Guasch, 2011: 46).

Guasch considera la obra de Walter Benjamin y Aby Warburg como un ámbito seminal de esa praxis que más tarde habría de alcanzar el estatuto de paradigma, y asocia a cada uno de estos pensadores con dos modalidades operativas distintas de lo que ella denomina la "máquina del archivo". Me parece, sin embargo, que 
para los fines de este trabajo es importante matizar la idea dicotómica según la cual Benjamin se aproximaría a los principios de "procedencia, homogeneidad y continuidad, al orden de la ley", mientras que Warburg estaría más cerca de "la pulsión de heterogeneidad y discontinuidad del archivo anómico” (2011: 15).

En realidad, la idea de una bifurcación al interior del paradigma del archivo fue originalmente descrita por Benjamin Buchloh en un artículo fundacional sobre el Atlas de Gerhard Richter titulado "Atlas/Archive" (1999). Ahí, Buchloh procede a un rastreo genealógico del trabajo de Richter dentro del horizonte de la "crisis de la memoria” de la Alemania de posguerra, que él describe como una "destrucción general de la identidad social", esto es, como un proceso en el que se habrían visto profundamente quebrantados los vínculos materiales que religaban tanto a los sujetos con los objetos, como a los objetos con las formas de su representación. Algo que quizás podríamos concebir también como la fase final del proceso de quebranto de la tradición del que en su momento hablara Hannah Arendt.

La primera o más evidente distinción del trabajo de Buchloh es relativa al contraste entre la aparente heterogeneidad del Atlas de Richter y el trabajo de otros artistas que le son contemporáneos, como por ejemplo Christian Boltanski, cuyas diversas colecciones logran proyectar una imagen de sorprendente continuidad temporal y tipológica. Sin embargo, el análisis genealógico de Buchloh logra un mayor alcance gracias a la realización de un "excurso", en el que se detiene en las prácticas del archivo de Walter Benjamin y Aby Warburg, y en el que lo que parecía una dicotomía aparecerá más bien como una combinatoria. Así lo sugiere, por ejemplo, la articulación descrita por Buchloh entre la radical heterogeneidad espaciotemporal de las imágenes dispuestas por Warburg sobre las planchas de su Atlas mnemosyne y la homogeneidad que, paradó- 
jicamente, genera la simultaneidad presencial de su reproducción fotográfica.

A juicio de Buchloh, esta combinatoria exhibe un paralelismo entre el montaje gráfico del Atlas y las prácticas artísticas de las vanguardias históricas de los años 20 (que en el caso del montaje literario del Libro de los pasajes fue hecho explícito por el propio Benjamin), cuyo sustrato típicamente modernista sería la confianza, o mejor dicho la esperanza depositada en las posibilidades emancipatorias de las tecnologías de reproducción de la imagen, y en particular de la fotografía:

[W] encounter in Warburg's project an almost Benjaminian trust in the universally emancipatory functions of technological reproduction and dissemination, those of the photographic imagen in particular. Thus, the extreme temporal and spatial heterogeneity of the Atlas's subjects is juxtaposed with the paradoxical homogeneity of their simultaneous presence in the space of photographic reproduction (Buchloh, 1999: 20).

Buchloh explica cómo, aun cuando en un primer momento las vanguardias (Dadaísmo, Cubismo, Futurismo, Constructivismo) contribuyeron al desmantelamiento del ideologema de la unidad y la totalidad mediante la implementación de estrategias que enfatizaron la discontinuidad y la fragmentación, es decir mediante la conformación de una estética iconoclasta del shock y el extrañamiento, su aporte epistemológico terminó por ser absorbido por un proyecto social de modernización perceptiva en el que cualquier dislocación es susceptible de una rearticulación sintáctica, y en consecuencia de ser integrada dentro de una lectura totalizante que sin embargo produce un efecto mimético de fragmentación, simultaneidad y diferencia estructural. 
Lo que esta recuperación epistemológica hace ver -y que resulta central tanto para el argumento de Buchloh como para los fines de este trabajo- es que el principio archivístico de acumulación aleatoria puede adquirir orientaciones contrastantes en función de las diversas circunstancias históricas bajo las cuales opera. Pues, como se puede constatar fácilmente hoy en día -en esta era en la que los sujetos son plenamente identificados como consumidores-, más que como procedimientos artísticos, en determinados contextos la anomia y la fragmentación llegan incluso a fungir como mecanismos de legitimación social encubiertos bajo el oropel de la independencia individual. $\mathrm{Y}$ es por ello que, sin renunciar a su trasfondo "antisubjetivista" (es decir uno para el que la subjetividad sólo puede ser comprendida en su conexión contingente con otras series históricas, sociales y culturales), las prácticas del archivo se habrían orientado hacia una modalidad más bien paratáctica, que pone el énfasis en la relativa homogeneidad de las fuentes y los materiales, desdramatizando y desespacializando las dinámicas del collage, al transformarlas en una mera colección de citas sometidas a la monotonía de su simple yuxtaposición en el archivo.

Así, resulta claro por qué para Buchloh el Atlas de Richter encarna una mutación anómica del paradigma del archivo:

The paratactic structure of Richter's Atlas then has to be positioned at the opposite end of spectrum of avant-garde positions. Neither the semiotic revolution of an aesthetics of structural difference that governed cubism, nor the mimetic internalization of an aesthetic of shock and mechanical dynamism that governed the futurist and constructivist model, nor the sudden juxtaposition of images and objects that would call up oneiric configurations and the logic of reification in the unconscious in the projects of the surrealist collage, can be quoted here as predecessors. Instead, what governs the photomontage aesthetic of Richter is preci- 
sely the mechanical alignment found in the order of the statical aesthetic of passive administration, the aesthetic of the lapidary archive. Against the gesture of rebellion and political agitation, against the posture of utopian political claims articulated by the avant-garde, against the infliction of the viewer with the shock of the uncanny, Richter proposes the repetitive litany of reproduction, presented in an administrative display, a pictorial order that is always already mired in the very power structure against which avant-garde gestures still claimed to rebel (1999: 32).

Más cercano al pesimismo de Kracauer que al supuesto optimismo emancipatorio de Benjamin, el trabajo de Richter formaría parte de una neovanguardia marcada por la pérdida del objeto (en este caso la imagen artística), derivada de su entera fagocitación por la industria cultural:

Richter sees the erosion of avant-garde positions and practices paradoxically embodied in the loss of painterly object and corroborated by the degree to which photographic reproduction enacts the intrusion of mechanisms of the culture industry within the traditionally exempted sphere of avant-garde culture itself. In this regard Richter's position on photography and painting as the lost object is comparable on the mourning of the loss of the object and the loss of the real articulated by Jean Baudrillard (Buchloh, 1999: 33).

No deja de llamar la atención, sin embargo, que esta presunta pérdida sumerja la praxis artística/archivística precisamente en la atmósfera del duelo. Pues como ya vimos, para la necroescritura y la desapropiación, el duelo era menos un padecimiento psíquico que un fundamento ético-político, derivado de una constatación en todo punto semejante a la que el propio Benjamin realizara en 
su estudio sobre las posibilidades de la reproducción técnica del arte, de 1936:

En sus estudios sobre la reproducción mecánica del arte, dentro de los cuales privilegiaba al fotográfico como el momento inaugural de la modernidad, Benjamin insistía -como también lo haría más tarde Roland Barthes- en que la fotografía no era una reproducción de lo que estaba ahí, sino de lo que no estaba. La fotografía lograba capturar, de hecho, el no-estar-ahí de las cosas. En otras palabras: la imagen era un largo luto; la imagen era una ausencia; la imagen era un anhelo [...] Si la fotografía captura lo que no está o, para decirlo con los propios términos de Benjamin, captura lo que sabemos que pronto no estará ahí; si más que reproducir anuncia, y de hecho evoca, la muerte y la ausencia de lo fotografiado, entonces la imagen se convierte en la tumba de los muertos vivientes y, como tal, cuenta su historia - una historia de fantasmas y de sombras- (Rivera Garza, 2013: 110).

Aquí vemos cómo las dicotomías que históricamente han tensado el paradigma del archivo se engolfan en las esferas del duelo y la melancolía. Y es que, como se verá, el paradigma archivístico está estrechamente vinculado con una forma de anomia que no puede ser comprendida desde una postura dicotómica, sino más bien dialéctica, por lo que la interrogación acerca del sustrato melancólico que acompaña las prácticas archivísticas habrá de llevarnos a reconsiderar la relación entre las estrategias del montaje y su dimensión utópica. Dicho de otro modo: si como se ha visto, la melancolía y el duelo constituyen el sustrato en el que se arraiga el paradigma del archivo, es importante dilucidar nuevamente en qué consiste la "débil fuerza mesiánica" - por usar los términos del propio Benjamin- que reside en esos frágiles remanentes que 
desde hace ya varias décadas artistas y escritores se empeñan en coleccionar con tanta minucia y tenacidad.

\section{Archivo y alegoría}

Ahora quisiera recuperar un fragmento de un texto titulado "Nymphae", que Giorgio Agamben publicó en 2003 a propósito de Aby Warburg y su "ciencia sin nombre". Ahí, el pensador italiano realiza una somera, pero aguda descripción de las categorías warburguianas tal y como se expresan en la conformación del Atlas mnemosyne, y dedica particular atención a la noción de Pathosformeln, que algunos traducen al castellano como "fórmula emotiva":

Al igual que las imágenes dialécticas en Benjamin y el símbolo en Vischer, los Pathosformeln [...] son recibidos en un estado de "ambivalencia latente no polarizada" y es sólo de esa manera, en el encuentro con un ser vivo, como pueden encontrar vida y polaridad. El acto de creación, en el cual lo singular -artista o poeta, tanto como el erudito y en último caso cualquier ser humano- se confronta con las imágenes, tiene lugar en una región central entre los dos polos de lo humano -en algo que podríamos definir como una zona de "indiferencia creativa", retomando una imagen de Salomón Friedlander que Benjamin gustaba citar-. El centro que aquí está en cuestión no es una noción geométrica, sino dialéctica: no el punto medio que separa dos segmentos en una línea sino el paso, a través de él, de una oscilación polar, [1]a imagen inmóvil de un ser pasajero. Ahora bien, esto significa que la operación que Warburg confía a su Atlas Mnemosyne es exactamente lo contrario de aquello que habitualmente se entiende bajo la rúbrica "memoria histórica” [, pues ésta] termina por revelarse, en el espacio de la 
memoria, como un auténtico abismo de sentido, el lugar mismo de su carencia (Agamben, 2003: 55). ${ }^{1}$

Lo que se desprende de la cita es que, conforme a la enseñanza de Warburg, debemos pensar la relación del archivo con la memoria en términos de una dialéctica que "no es dicotómica y sustancial, sino bipolar y tensional". Una que no sólo es inseparable de los objetos que niega, sino en la que "éstos pierden su identidad y devienen los dos polos de una misma tensión dialéctica, cuya evidencia culmina en la inmovilidad, como en una danza por fantasmata" como la que describe Agamben al inicio de su escrito, apelando a un texto del quattrocento sobre el arte de bailar y danzar de Domenico da Pacienza. ${ }^{2}$ Pero es el propio Benjamin quien, en su ensayo sobre el drama barroco alemán, asocia su concepción de la alegoría - de suma importancia para su proyecto de filosofía histórica- con las concepciones de Warburg, al describirla exactamente como una supervivencia o Nachleben.

En una afirmación en la que evidentemente se desmarca de los lugares comunes acerca de los orígenes de la alegoresis, Benjamin señala que ésta "no surgió en calidad de arabesco escolástico para la representación antigua de los dioses". Ya que, en realidad,

${ }^{1}$ Este texto permaneció inédito antes de que fuera publicado en francés y, hasta donde tengo noticia, aún no se ha publicado en castellano. La versión al castellano que aquí ofrezco es mía.

2 "Para Domenichino, la danza es entonces esencialmente una operación realizada sobre la memoria, una composición de fantasmas en una serie temporal y espacialmente ordenada. El verdadero lugar del bailarín no radica ni en su cuerpo ni en su movimiento, sino en la imagen en tanto 'cabeza de Medusa', como una pausa no inmóvil, sino cargada, al mismo tiempo, de memoria y energía dinámica” (Agamben, 2003: 41). 
[... si la Iglesia hubiera podido eliminar a los dioses arrancándolos de la memoria de sus fieles, la alegoresis nunca habría nacido, pues no es el monumento epigonal de ninguna victoria; sino, antes que eso, la palabra que debe exorcizar un resto aún intacto de la vida antigua [...] Pues la comprensión de lo caduco de las cosas y esa preocupación por salvarlo en lo eterno es en lo alegórico uno de los motivos más potentes. En el arte, como en la ciencia y el Estado, nada había durante la Alta Edad Media que pudiera compararse a las ruinas que en todos estos ámbitos eran el legado de la Antigüedad. El conocimiento de la caducidad se derivaba de una intuición ineluctable, de la misma manera que unos siglos más tarde, en la época de la Guerra de los Treinta Años, saltaría a los ojos de la humanidad europea. Se ha de observar al respecto que quizás las devastaciones más palmarias no impongan a los hombres estas experiencias con más amargura que la transformación de unas normas legales que antes se presentaban con la pretensión de lo eterno, algo que en aquel tiempo de transición se consuma de modo particularmente visible. La alegoría se asienta con mayor permanencia allí donde caducidad y eternidad chocan más frontalmente (Benjamin, 2006: 445-446).

Del choque frontal que tiene lugar en el origen, en la arjé misma de la alegoría, no puede derivarse sino una tensión dialéctica que, más que con la catástrofe de la Guerra Civil o con el inevitable desmoronamiento de los imperios, tiene que ver con el declive de unas "normas legales que antes se presentaban con la pretensión de lo eterno", es decir, con la propensión melancólica que germina en los intersticios de un nomos desfalleciente o ya desfallecido. Y éste es precisamente el espacio de la memoria histórica tal y como lo describía Agamben, es decir, "como un auténtico abismo de sentido o como el lugar mismo de su carencia". 
Según Benjamin, para la conciencia alegórica la ruina, al igual que la calavera, es la cifra de una naturaleza caída donde las cosas difieren de sí mismas, se arrebatan a sus nombres y, junto con el sentido que débilmente las ataba a ellos, perecen en la noche del decurso que llamamos historia, no sin dejar el rastro material en el que anida su huella espectral. Ahora bien, en un ensayo sobre las categorías lingüísticas e históricas en el pensamiento de Benjamin, el propio Agamben explica lúcidamente este proceso histórico:

Dado que el hombre puede recibir los nombres, que siempre lo preceden, sólo a través de la transmisión, el acceso a esta esfera fundamental del lenguaje está mediado y condicionado por la historia. El hombre hablante no inventa los nombres ni éstos emanan de él como una voz animal: ellos más bien le advienen, dice Varrón, descendiendo, es decir a través de una transmisión histórica. Los nombres solamente nos pueden ser dados, tràditi; el discurso, en cambio, es objeto de un ars, susceptible de un saber técnico-racional [...] La razón no puede llegar al fondo en los nombres (los vocablos), no puede alcanzarlos porque [...] ellos le advienen históricamente, descendiendo. Este infinito "descenso" de los nombres es la historia [...] La historia es la cifra de la sombra que vela el acceso del hombre al plano de los nombres: la historia está en lugar de los nombres (Agamben, 2007: 47-48).

Desde esta perspectiva, la tradición es precisamente el manto, el entramado que arropa al hombre, brindando sentido a los nombres en este "descenso" -ocultándolos-. Pero, como lo señala claramente Hannah Arendt, para quien el pasado posee autoridad en tanto ha sido transmitido como tradición, y la autoridad se convierte en tradición en tanto se presenta desde un punto de vista histórico, Benjamin "sabía que la ruptura en la tradición y la pérdida de autoridad en su vida eran irreparables", por lo cual habría 
llegado a la conclusión de que "tenía que descubrir nuevas formas de tratar con el pasado". En otras palabras, descubrió que "el carácter transmisible del pasado había sido reemplazado y que en lugar de su autoridad había ido surgiendo, en forma gradual, un poder extraño" (Arendt, 1990: 178), a saber, el destructivo poder de citar el pasado a la manera del coleccionista. Pues para Benjamin "el verdadero coleccionista saca al objeto de su entorno funcional", sometiéndolo a un nuevo ordenamiento, "sorprendente, incomprensible para el profano", en el que el objeto es inseparable de la totalidad de datos objetivos de su pasado ("su anterior propietario, su precio de adquisición, su valor, etc.”). En este destino del objeto es posible leer el esbozo de una "enciclopedia mágica" y un "orden del mundo" (Benjamin, 2005: 225) que sin duda hacen pensar en un montaje como el que constituye el propio Libro de los pasajes.

La figura del coleccionista, "tan anticuada como la del flâneur", prosigue Arendt, "podía asumir rasgos tan característicos en Benjamin porque la historia en sí (es decir, la ruptura en la tradición que tuvo lugar a comienzos de este siglo) ya lo había liberado de la tarea de destrucción y sólo necesitaba inclinarse para seleccionar sus fragmentos de la pila de escombros" (1999: 185). Lo cual equivale a decir que el insólito orden del mundo que surge del montaje histórico del coleccionista encuentra su cifra originaria en el destino material de la ruina y el escombro, en la dispersión de lo fragmentario:

Al gran coleccionista le conmueven de un modo enteramente originario la confusión y la dispersión en que se encuentran las cosas en el mundo. Este mismo espectáculo fue el que tanto ocupó a los hombres del Barroco: en particular, la imagen del mundo del alegórico no se explica sin el impacto turbador de este espectáculo. El alegórico constituye por decirlo así el polo opuesto del coleccionista. Ha renunciado a iluminar las cosas mediante la in- 
vestigación de lo que sea afín o les pertenezca. Las desprende de su entorno, dejando desde el principio a su melancolía iluminar su significado. El coleccionista, por contra, junta lo que encaja entre sí; puede de este modo llegar a una enseñanza sobre las cosas mediante sus afinidades o mediante su sucesión en el tiempo. No por ello deja de haber en el fondo de todo coleccionista un alegórico, y en el fondo de todo alegórico un coleccionista, siendo esto más importante que lo que los separa. En lo que toca al coleccionista, su colección jamás está completa; y aunque sólo le faltase una pieza, todo lo coleccionado seguiría por eso siendo fragmento, como desde el principio lo son las cosas para la alegoría. Por otro lado, precisamente el alegórico, para quien las cosas sólo representan las entradas de un secreto diccionario que dará a conocer sus significados al iniciado, jamás tendrá suficientes cosas, pues ninguna de ellas puede representar a las otras en la medida en la que ninguna reflexión puede prever el significado que la melancolía será capaz de reivindicar en cada una (Benjamin, 2005: 229).

Así, el coleccionista y el alegórico no se oponen como si se tratase de dos figuras históricas o cognoscitivas distintas, sino como dos momentos de una tensión dialéctica que constituye una misma posibilidad del montaje ante la historia en tanto ruina y fragmento: la asignación de significados alegóricos mediante la melancolía, y su articulación fetichista en una "enciclopedia mágica”, es decir, mediante un montaje que jamás se articula como totalidad, sino que, del mismo modo que Benjamin lo refiere en relación al traductor frente a su original, asume la "tarea" de ensamblar hasta en el más mínimo detalle los fragmentos dispersos del jarrón roto que son la lengua y la historia -el "descenso" de los nombres-, no para unirlos borrando las fisuras, sino para hacer posible su reconocimiento en tanto parte de una lengua universal, mesiánicamente "reconciliada" pero constituida de puros fragmentos. Fragmento 
de un fragmento, la traducción, al igual que la práctica emblemática barroca, la crítica histórica o la conformación artística del archivo, continúa incesantemente rompiendo el jarrón, sin jamás reconstituirlo, como observa Paul de Man (1986: 91).

Ambos, el melancólico y el fetichista, saben en el fondo que el objeto está originariamente perdido: que nunca hubo jarrón sino como fantasmagoría. Si el melancólico efectúa el luto de un objeto que jamás ha existido, y que sólo accede a la realidad a través de la ficción de su pérdida -el objeto total, el único digno de su deseo-, por su parte el fetichista niega la pérdida de un objeto también inexistente -el pene materno- mediante su sustitución a través de un objeto parcial, en cuya factura exhibe la cifra de su inexistencia. En ambos casos, el objeto perdido, que está desde siempre fracturado, es el espacio intermedio, intersticial, cabalmente dialéctico, en el que emerge la significación en tanto Nachleben, en tanto supervivencia fantasmagórica:

No ya fantasma y todavía no signo, el objeto irreal de la introyección melancólica abre un espacio que no es ni la alucinada escena onírica de los fantasmas ni el mundo indiferente de los objetos naturales; pero en este lugar intermedio y epifánico, situado en la tierra de nadie entre el amor narcisista de sí y la elección objetual externa, es donde podrán colocarse un día las creaciones de la cultura humana, [...] de las formas simbólicas y de las prácticas textuales a través de las cuales el hombre entra en contacto con un mundo que le es más cercano que cualquier otro y del que dependen, más directamente que de la naturaleza física, su felicidad y su desventura (Agamben, 1995: 63).

No es difícil observar que la tradición sin fisuras sería precisamente ese objeto total, preadánico, que sólo puede existir en la imagen de su pérdida. Y que el recuerdo de su inexistencia, alojado 
en la ruinosa materialidad del fragmento es aquello que convoca a hacer valer aquella "débil fuerza mesiánica" de la historia a contrapelo, que es cabalmente una historia espectral:

El pasado comporta un índice secreto por el cual remite a la redención. ¿No nos roza, pues, a nosotros mismos un soplo del aire que envolvió a los antecesores? ¿No existe en las voces a que prestamos oído un eco de las ahora enmudecidas? ¿No tienen las mujeres a las que cortejamos unas hermanas que ellas no han conocido ya? Si es así, hay entonces una cita secreta entre las generaciones pasadas y la nuestra. Y sin duda, entonces, hemos sido esperados en la tierra. A nosotros, entonces, como a cualquier otra generación anterior, se nos habrá dotado de una débil fuerza mesiánica a la que el pasado posee un derecho (Benjamin, 2008: 306).

Al igual que el alegorista melancólico, las prácticas del archivo contemporáneas trabajan sobre el trasfondo de la fantasmagoría de la totalidad, del objeto pleno o de la tradición sin fisuras; pero, como el coleccionista, que es su complemento dialéctico, lo hacen a contrapelo, es decir distanciándose, quebrantando la continuidad facticia de la tradición y sometiéndola al montaje de la singularidad de las ruinas, revelando así su índice mesiánico, esto es, su posibilidad de detonar desde el presente la memoria fragmentaria de su pertenencia a una lengua (o una historia) universal inexistente pero siempre ya acaecida y a la vez siempre inminente. Para actualizar, mediante la memoria espectral, la fuerza de su irrealidad utópica.

$\mathrm{Si}$, como reza la séptima tesis sobre el concepto de historia -con fuertes resonancias para nosotros aquí y ahora-, la "tradición de los oprimidos nos enseńa que el 'estado de excepción en que vivimos en sin duda la regla", es porque, desde siempre, el nomos ha estado quebrantado. Por lo que el saber de ese objeto perdido, que sólo 
existe mediante la apropiación de su pérdida, tiene en la tristeza un ingrediente que se tensa productivamente con la paradójica y minuciosa construcción de una totalidad fragmentaria (de una tradición a contrapelo, es decir ruinosa), propicia para la escucha de los índices mesiánicos de la irrealidad que atraviesa los objetos, y para su organización dentro del archivo de una "enciclopedia mágica” en la que se haga posible esa redención de los espectros del pasado y el presente, sin la cual la nuestra resultaría definitivamente inviable.

\section{Bibliografía}

Agamben, Giorgio, 1995, Estancias. La palabra y el fantasma en la cultura occidental Tomás Segovia (trad.), Editorial Pre-textos, Valencia.

, 2004, Image et mémoire. Ecrits sur l'image, la danse et le cinema, Ed. Descleé de

Brouwer, Francia.

,2007, La potencia del pensamiento. Ensayos y conferencias, Ed. Adriana Hidalgo, Buenos Aires.

Arendt, Hannah, 1990, Hombres en tiempo de oscuridad, Claudia Ferrari (trad.), Editorial Gedisa, Barcelona.

Benjamin, Walter, 2005, Libro de los pasajes, Luis Fernández Castañeda, Isidro Herrera y Fernando Guerrero (trad.), Akal, Madrid.

, 2006, El origen del Trauerspiel alemán. Obras I, Alfredo Brotons Muñoz (trad.), Editorial Abada, Madrid.

, 2008, Sobre el concepto de Historia. Obras I, Alfredo Brotons Muñoz (trad.), Editorial Abada, Madrid. 
Buchloh, Benjamin, 1999, "Atlas/Archive", en The optic of Walter Benjamin, Alex Coles (ed.), Black Dog Publishing, Londres, pp. 12-35.

De Man, Paul, 1986, The Resistance to Theory, University of Minnesota Press, Minneapolis/Londres.

Derrida, Jacques, 1995, Mal d'archive. Une impression freudienne, Galilée, Paris.

Guasch, Ana María, 2011, Arte y archivo, 1920-2010. Genealogías, tipologias y discontinuidades, Akal, Madrid.

Mbembe, Achille, 2011, Necropolitica, Elisabeth Falomir Archambault (trad.), Ed. Melusina, Tenerife.

Rivera Garza, Cristina, 2013, Los muertos indóciles. Necroescrituras y desapropiación, Tusquets, México. 